\title{
Terson's syndrome following an aneurysmal subarachnoid hemorrhage: an imaging prognostic finding you should recognize
}

Síndrome de Terson após hemorragia subaracnoidea: um achado prognóstico de imagem que você deve reconhecer

Douglas Mendes Nunes', Bruna Garbugio Dutraํ․, Antônio Carlos Martins Maia Júnior¹, Reginaldo Carlos

Boni², Antônio José da Rocha

Terson's Syndrome (TS) was originally described as intraocular hemorrhage associated with aneurysmal subarachnoid hemorrhage $(\mathrm{SAH})^{1}$. It is a consequence of sudden rise in intracranial pressure (IP) that reduces venous return to the cavernous sinus or obstruct the retinochoroidal anastomoses and central retinal vein, culminating in venous stasis and ocular hemorrhage (Figure). TS has also been reported in nonaneurysmal SAH, severe traumatic injuries or venous thrombosis ${ }^{2}$.

Current literature has highlighted TS as an important life-threatening prognostic finding ${ }^{3,4}$. Recognizing TS on fundoscopy or CT is recommended and effective control of IP is imperative to reduce the risk of mortality in this critical setting ${ }^{5}$.
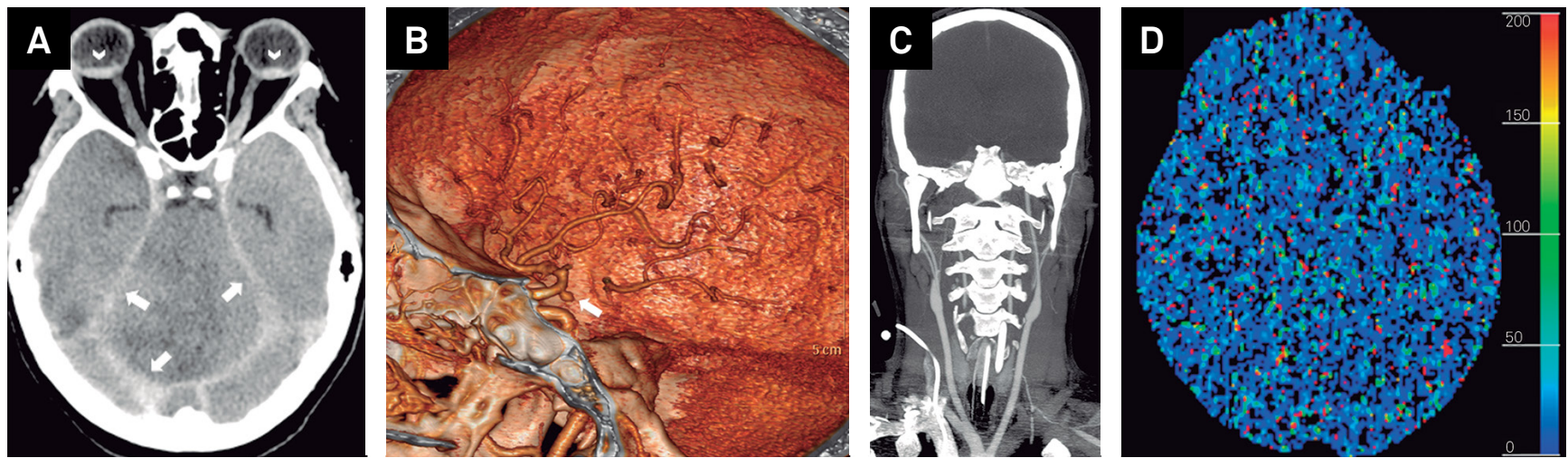

Figure. 37 year-old woman with sudden headache progressed to seizures and decreased level of consciousness. Nonenhanced CT (A) showed basilar cisterns and sulcal effacement due to intracranial hypertension, additionally to subarachnoid hemorrhage that thickens and increases the attenuation of the tentorium cerebelli bilaterally (arrows). Note bilateral intraocular hemorrhage (arrowheads). The 3D-reconstruction of CTA (arterial phase) showed a berry aneurysm (arrow) in the supraclinoid segment of the right internal carotid artery (B). The coronal reformatted CTA image (C) and CT perfusion axial image (D), performed 4 days later, depicted absence of contrast opacification of intracranial vessels and diffusely absent cerebral blood flow, endorsing the concurrent diagnosis of brain death in the follow-up.

1. Terson A. De l'hémorrhagie dans le corps vitre au cours de l'hémorrhagie cerebrale. Clin Ophthalmol. 1900;6:309-12.

2. McCarrom MO, Alberts MJ, McCarron P. A systematic review of Terson's syndrome: frequency and prognosis after subarachnoid haemorrhage. J Neurol Neurosurg Psychiatry. 2004;75:491-3. doi:10.1136/jnnp.2003.016816.

3. Watanabe S, Bordon A, Cavalheiro S, Sallum J, Farah M. Terson's syndrome as a prognostic factor for mortality of spontaneous subarachnoid hemorrhage. Acta Ophthalmol. 2011;89(6):544-7. doi:10.1111/j.1755-3768.2009.01735.x.
4. Czorlich P, Skevas C, Knospe V, Vettorazzi E, Richard G, Wagenfeld $L$ et al. Terson syndrome in subarachnoid hemorrhage, intracerebral hemorrhage, and traumatic brain injury. Neurosurg Rev. 2015;38(1):129-36. doi:10.1007/s10143-014-0564-4.

5. Stienen MN, Lücke S, Gautschi OP, Harders A. Terson haemorrhage in patients suffering aneurysmal subarachnoid haemorrhage: a prospective analysis of 60 consecutive patients. Clin Neurol Neurosurg. 2012;114(6):535-8. doi:10.1016/j.clineuro.2011.10.034.

'Santa Casa de Misericórdia de São Paulo, Setor de Neurorradiologia, São Paulo SP, Brasil;

2Santa Casa de Misericórdia de São Paulo, Serviço de Procura de Órgãos e Tecidos, São Paulo SP, Brasil.

Correspondence: Antonio José da Rocha; Santa Casa de Misericórdia de São Paulo, Serviço de Diagnóstico por Imagem; Rua Dr. Cesário Motta Junior 112; 01221-020 São Paulo SP, Brasil; E-mail: a.rocha@uol.com.br

Received 06 October 2015; Received in final form 09 March 2016; Accepted 28 March 2016. 